4. Fowler AJ, Ahmad T, Phull MK, Allard S, Gillies MA, Pearse RM. Meta-analysis of the association between preoperative anaemia and mortality after surgery. $\mathrm{Br} J$ Surg. 2015;102:1314-24.
5. Munoz M, Ariza D, Gomez-Ramirez S, Hernandez P, Garcia-Erce JA, Leal-Noval SR. Preoperative anemia in elective cardiac surgery: prevalence, risk factors, and influence on postoperative outcome. Transfus Altern Transfus Med. 2010;11:47-56.
See Article page 997.

\section{Commentary: Optimizing oxygen delivery during cardiopulmonary bypass to minimize morbidity and mortality: Have our goals been achieved?}

\section{Harold L. Lazar, MD}

Strategies involving goal-directed perfusion during cardiopulmonary bypass (CPB) have been associated with decreased acute kidney injury (AKI) following cardiac surgery. ${ }^{1}$ However, it is unclear as to what defines goaldirected perfusion during $\mathrm{CPB}$ and whether it can reduce not only AKI, but all morbidity and mortality in all patients undergoing cardiac surgery on CPB.

In this edition of the Journal, Magruder and colleagues ${ }^{2}$ report the relationship between oxygen delivery $\left(\mathrm{DO}_{2}\right)$ during CPB and morbidity and mortality in 834 cardiac surgery patients on CPB using an electronic perfusion medical record system (Quantum Perfusion Systems, Spectrum Medical, Fort Mill, SC) that provides continuous online data of flow parameters and hemodynamic variables, including $\mathrm{DO}_{2}$, blood pressure, cardiac index, pump flow, and hemoglobin $(\mathrm{Hgb})$. The institutional target for $\mathrm{DO}_{2}$ was at least $260 \mathrm{~mL} / \mathrm{O}_{2} / \mathrm{min} / \mathrm{m}^{2}$, which was achieved by optimizing flow parameters, reinfusing blood sequestered in the operative field, and transfusing blood products. The primary outcome was the occurrence of a composite of Society of Thoracic Surgeons (STS) morbidity/mortality outcomes (mortality, postoperative renal failure, surgical reexploration,

\footnotetext{
From the Division of Cardiac Surgery, Boston University School of Medicine, Boston, Mass.

Disclosures: The author reported no conflicts of interest.

The Journal policy requires editors and reviewers to disclose conflicts of interest and to decline handling or reviewing manuscripts for which they may have a conflict of interest. The editors and reviewers of this article have no conflicts of interest.

Received for publication Dec 5, 2020; revisions received Dec 5, 2020; accepted for publication Dec 7, 2020; available ahead of print Jan 21, 2021.

Address for reprints: Harold L. Lazar, MD, 80 East Concord St, Boston, MA 02467 (E-mail: harold.1.lazar@gmail.com).

J Thorac Cardiovasc Surg 2022;164:1009-10

$0022-5223 / \$ 36.00$

Copyright (c) 2020 by The American Association for Thoracic Surgery

https://doi.org/10.1016/j.jtcvs.2020.12.048
}

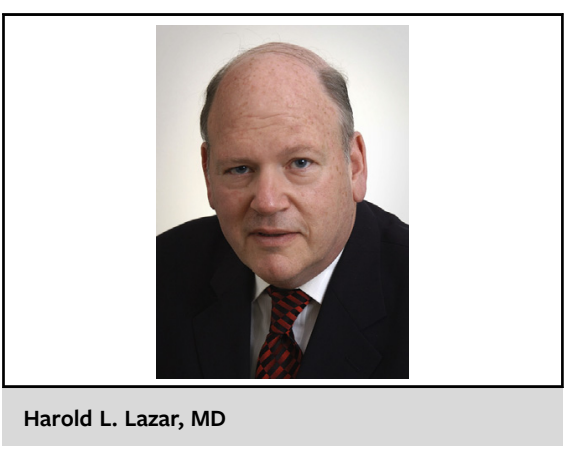

CENTRAL MESSAGE

Optimizing oxygen delivery during cardiopulmonary bypass may minimize morbidity and mortality.

postoperative prolonged intubation for $>24$ hours, deep sternal wound infection, and stroke). Although a $\mathrm{DO}_{2}<280$ was associated with an increased incidence of the composite STS outcome, the increase failed to reach statistical significance $(P=.07)$. However, in those patients undergoing nonisolated CABG procedures, a $\mathrm{DO}_{2}<280$ was significantly associated with the primary outcome $(P=.02)$. This was driven largely by an increased incidence of prolonged ventilation for $>24$ hours when the $\mathrm{DO}_{2}$ was $<280(P=.04)$. STSdefined renal failure was not associated with $\mathrm{DO}_{2}$ in the entire patient cohort $(P=.07)$; however, stage 1 AKI within 72 hours of surgery was independently associated with a $\mathrm{DO}_{2}<280(P=.02)$. Overall, patients with a preoperative glomerular filtration rate GFR $<65$ and a $\mathrm{Hgb}$ level $<12.5 \mathrm{mg} / \mathrm{dL}$ appeared to be most vulnerable for morbidity and mortality when the $\mathrm{DO}_{2}$ was $<280$.

This study has several limitations, which the authors have acknowledged. The sample size was relatively small, which limited the ability to determine causality. Data obtained during the period of weaning from CPB was included, which may have altered the outcomes. The interventions used to increase $\mathrm{DO}_{2}$ when values fell below 260 were not uniform. The database could not determine when patients were actively treated to maintain the target $\mathrm{DO}_{2}$, 
and whether the initiated treatment resulted in improved outcomes. No data were provided on the relationship between low $\mathrm{DO}_{2}$ and serum lactate, glucose, and cerebral oximetry on $\mathrm{CPB}$, and whether correcting these parameters during CPB would improve postoperative outcomes. Finally, there were no controls, that is, a group of patients undergoing CPB managed without a targeted $\mathrm{DO}_{2}$.

Despite these limitations, the authors are to be congratulated for developing an innovative tool to help optimize $\mathrm{DO}_{2}$ during $\mathrm{CPB}$ and to study its effects on reducing morbidity and mortality. Their data suggest that patients with preoperative anemia and reduced GFR may be most susceptible to increased morbidity and mortality when $\mathrm{DO}_{2}$ is $<280$. This also may be reflective of the increased incidence of comorbidities in these patients. It will be important to determine whether optimizing $\mathrm{DO}_{2}$ in these high-risk patients will be successful in minimizing postoperative complications. $\mathrm{DO}_{2}$ is dependent on flow and $\mathrm{Hgb}$, but it also may be important to study the effects of perfusion pressure in these more vulnerable patients.

The authors should be encouraged to continue their investigations on the effect of $\mathrm{DO}_{2}$ during $\mathrm{CPB}$ with prospective, randomized studies in patients targeted to achieve a
$\mathrm{DO}_{2}$ of 280 versus those receiving standard of care perfusion practices without a targeted $\mathrm{DO}_{2}$. These studies should be sufficiently powered to achieve statistical significance among the 6 STS performance variables. Data during the weaning period from CPB should not be included, but important variables, such as lactate, serum glucose, inotropic and vasopressor support, and cerebral oximetry, are essential. An algorithm for various interventions to be implemented to achieve a $\mathrm{DO}_{2}$ of 280 should be in place, and the combination of flow and pressure in addition to flow and Hgb also should be studied. Data derived from these studies will be essential for determining whether optimizing $\mathrm{DO}_{2}$ during $\mathrm{CPB}$ will help achieve the critical goals of minimizing morbidity and mortality in cardiac surgery patients.

\section{References}

1. Magruder JT, Crawford TC, Harness HL, Grimm JC, Suarez-Pierre A, Wierschke C, et al. A pilot goal-directed perfusion initiative is associated with less acute kidney injury after cardiac surgery. J Thorac Cardiovasc Surg. 2017; 153:118-25.

2. Magruder JT, Weiss SJ, DeAngelis KG, Haddle J, Desai ND, Szeto WY, et al. Correlating oxygen delivery on cardiopulmonary bypass with Society of Thoracic Surgeons outcomes following cardiac surgery. J Thorac Cardiovasc Surg. 2022; 164:997-1007. 